\title{
Meninas Digitais Regional Mato Grosso: Práticas Motivacionais no Ensino Médio para a Equidade de Gêneros nas Carreiras e Cursos de Computação e Tecnologias
}

\author{
Karen da Silva Figueiredo ${ }^{1}$, Pedro Clarindo da Silva Neto ${ }^{2}$, Cristiano Maciel $^{1}$ \\ ${ }^{1}$ Instituto de Computação - Universidade Federal de Mato Grosso (UFMT) \\ Av. Fernando Corrêa da Costa, 2367, Boa Esperança - Cuiabá- MT - Brasil \\ ${ }^{2}$ Instituto Federal de Mato Grosso - Campus Avançado de Tangará da Serra (IFMT) \\ Rua 28, 980N, Jd Horizonte - 78300-000 - Tangará da Serra - MT - Brasil. \\ karen@ic.ufmt.br, pedro.neto@tga.ifmt.edu.br, cmaciel@ufmt.br
}

\begin{abstract}
This paper presents the actions realized between 2015 and 2016 by the project Digital Girls of Regional Mato Grosso which aims to realize motivational and informational practices with High School students in the state of Mato Grosso. The purpose of the project is to achieve gender equality in careers and courses of Computing in the region by encouraging and promoting women's participation.
\end{abstract}

Resumo. Este trabalho apresenta as ações do projeto Meninas Digitais da Regional Mato Grosso que tem como propósito a realização de práticas de caráter motivacional e informativo com alunas de Ensino Médio no estado de Mato Grosso, visando a equidade de gênero nas carreiras e cursos das áreas de Computação e Tecnologias da região pelo incentivo e promoção da participação feminina. Este artigo tem como objetivo relatar os trabalhos realizados pela regional Mato Grosso durante o período de 2015-2016.

\section{Introdução}

De modo geral, as pesquisas costumam revelar que as mulheres são minoria na Computação. Entretanto, dados recentes revelam um cenário ainda pior: as mulheres brasileiras perderam representatividade nos cursos relacionados à Computação. Em 1991, as mulheres somavam 34,9\% dos alunos matriculados em cursos de Computação e afins, em 2013 passaram a representar 15,53\% dos ingressantes, e destas apenas 13,6\% concluem o curso, segundo o Censo da Educação Superior [INEP 2015].

Buscando uma solução para o cenário descrito, diversas iniciativas estão emergindo em prol do incentivo e promoção da participação feminina nas áreas de Computação e afins. Uma destas iniciativas é o Programa Meninas Digitais da Sociedade Brasileira de Computação (SBC) que tem como objetivo divulgar a área de Computação para despertar o interesse de estudantes (principalmente do gênero feminino) do ensino médio/tecnológico ou dos anos finais do ensino fundamental [Maciel e Bim 2016]. Deste programa, surgiu uma série de projetos em instituições no Brasil, sendo uma delas o Meninas Digitais Regional Mato Grosso (MD-MT). 
O MD-MT propõe a realização de ações estratégias que possam motivar alunas do Ensino Médio/Tecnológico a seguirem carreiras nas áreas de tecnologia. Este projeto teve início em maio de 2015 e possui um cronograma de longo prazo, prevendo a execução de atividades em diferentes municípios do estado de Mato Grosso. O projeto possui caráter extensionista, mas suas ações buscam estreitar os laços entre ensino, pesquisa e extensão.

O MD-MT tem como objetivo geral a realização de práticas de caráter motivacional e informativo com alunas de Ensino Médio no estado de Mato Grosso visando à equidade de gêneros nas carreiras e cursos das áreas de Computação e Tecnologias da região pelo incentivo e promoção da participação feminina.

A fim de alcançar o objetivo geral do projeto, o mesmo conta com os seguintes objetivos específicos:

1) Realização de pesquisas sobre os índices estaduais de participação feminina em Computação e Tecnologias nas IES e no mercado do estado;

2) Produção de materiais informativos sobre os cursos de Computação e Tecnologias do estado e sobre as diversas carreiras possíveis nas áreas de Computação e Tecnologias;

3) Planejamento, elaboração e execução de atividades motivacionais e informativas com alunas de Ensino Médio sobre conteúdos, disciplinas e carreiras das áreas de Computação e Tecnologias;

4) Realização de atividades integradoras com as alunas de Ensino Médio e alunas de graduação, alunas de pós-graduação, professores e outros profissionais das áreas de Computação e Tecnologias;

5) Avaliação dos impactos das atividades realizadas pelo projeto no cenário estadual.

Para alcançar cada um dos objetivos específicos, o projeto Meninas Digitais Regional Mato Grosso possui uma série de ações estratégicas programadas. Na próxima seção, são descritos de forma breve, devido ao limite deste artigo, os resultados preliminares das ações executadas no primeiro ano do projeto (2015-2016).

\section{Práticas Realizadas}

No período de 2015-2016, o Meninas Digitais Regional Mato Grosso já realizou diversas práticas informativas e motivacionais com alunas do Ensino Médio, Fundamental, Superior e a comunidade em geral, atendendo mais de 580 pessoas de 12 municípios do estado. As ações do projeto são concentradas principalmente nos municípios de Cuiabá (capital do estado) e Tangará da Serra (pólo do projeto no interior).

A seguir, são listadas algumas das principais práticas realizadas pelo projeto neste período (veja mais detalhes no site ${ }^{1}$ ), enumeradas por objetivo supracitado:

http://meninasdigitaismatogrosso.org/ 
1.1) Levantamento e análise dos dados da participação feminina no curso de Bacharelado de Sistemas de Informação no estado [Mendes e Figueiredo 2016];

2.1) Produção e distribuição de material gráfico impresso (flyer) sobre os cursos de Computação e afins do estado e sobre as diferenças entre eles;

2.2) Produção e divulgação de material gráfico e informativo online sobre diversas temáticas relacionadas à mulheres na Computação e tecnologias através do site do projeto $^{2}$;

3.1) Realização de oficinas de MIT App inventor, Desenvolvimento de Jogos (Construct2), Programação Web (HTML e CSS), História da Computação, Gêneros e Tecnologia, Edição de Som Digital com alunas de Ensino Médio;

3.2) Realização de oficida de programação básica com a Hora do Código com alunos de Ensino Médio e Fundamental;

3.3) Realização de palestras sobre equidade de gêneros nas carreiras e cursos de Computação e Tecnologias em empresas, IES e eventos do estado ${ }^{3}$;

3.4) Participação com alunas de Ensino Superior na Maratona de Programação da SBC 2015;

3.5) Participação com alunas de Ensino Médio e Superior no Technovation Challenge 2016;

4.1) Realização de eventos: $1^{\circ}$ Encontro App Inventor, I Fórum Meninas Digitais Regional MT: Tangará da Serra ${ }^{4}$, CineDebate do filme CODEGIRL, Apresentação do Technovation Challenge Brasil 2016 em comemoração ao aniversário da Ada Lovelace, $1^{\circ}$ Fórum TPM - Teorias, Programação e Métodos, Mesa Redonda Meninas Digitais: Iniciativas inclusivas da mulher no mundo tecnológico;

4.2) Participação com alunas de Ensino Técnico de Informática em desfile cívico municipal;

5.1) Participação em eventos nacionais para apresentação e discussão dos resultados do projeto: $12^{\text {a }}$ Semana Nacional de Ciência, Tecnologia e Inovação ${ }^{5}$, Computer on the Beach 2016, $9^{\circ}$ WIT Women in Information Technology e Fórum Meninas Digitais 2015, I Diálogo Elas nas Exatas.

A Figura 1 apresenta alguns registros imagéticos de algumas das ações previamente citadas.

\footnotetext{
2 http://meninasdigitaismatogrosso.org/

3 http://www.bemnoticias.com.br/cidades/id-

338848/forum_regional_apresenta_projeto_meninas_digitais

$4 \mathrm{http}: / /$ www.radiopioneira.com.br/index.php/new/31474/1-forum-do-projeto-meninas-digitais-erealizado-no-ifmt-tangara

5 https://sbcmt.wordpress.com/2015/10/08/ri-da-ufmt-cuiaba-leva-a-semana-da-sbc-para-a-12asemana-nacional-de-ciencia-tecnologia-e-inovacao/\#more-195
} 

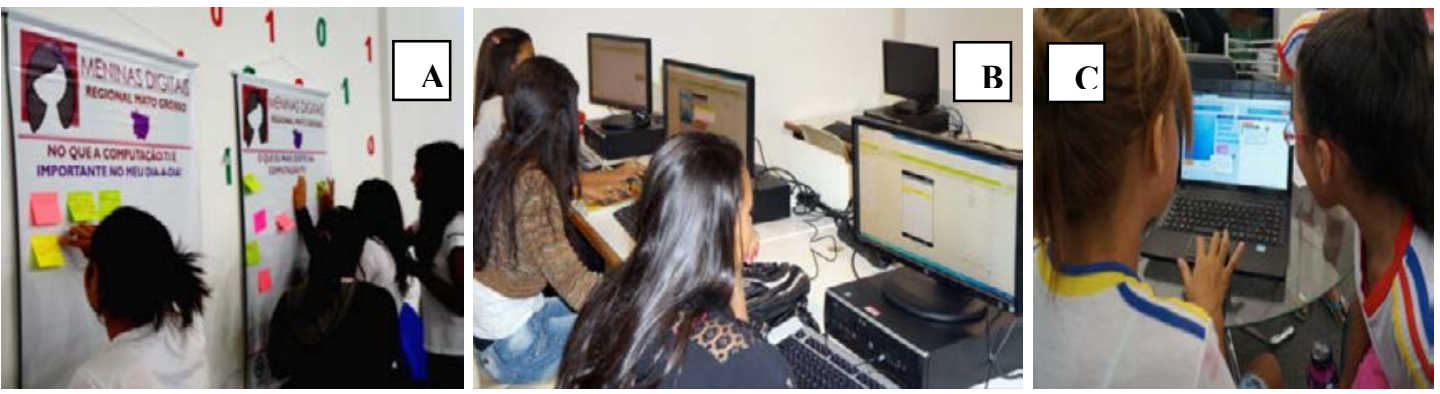

Figura 1. Fotos de oficinas do projeto: A) oficina Gêneros e Tecnologias com alunas de Ensino Médio; B) oficina MIT App Inventor com alunas de Ensino Médio; C) oficina Hora do Código com alunas de Ensino Fundamental e Médio

Observou-se o sentimento de apropriação das participantes das ações, no sentido de entenderem que podem ser estudantes e profissionais da área da computação, de que mulheres contribuíram e contribuem de forma significativa para a ciência e que também pode ser divertido trabalhar nessa área, desmistificando estereótipos comuns. Foi possível observar também a assiduidade na frequência nos encontros periódicos no período de execução apresentado.

\section{Conclusões}

Como parte da sociedade, as universidades têm papel fundamental na formação dos profissionais e devem criar estratégias de conscientização da população com o intuito de aumentar a visibilidade dos problemas referentes às relações de gêneros na educação e no mercado. Acredita-se que iniciativas como o projeto Meninas Digitais Regional Mato Grosso são fundamentais para motivar e informar as alunas com relação aos cursos e carreiras de Computação e afins, enquanto estas estão em um momento de amadurecimento e escolhas no Ensino Médio, principalmente em uma região que aparece em penúltimo lugar na quantidade de cursos da área [SBC 2013], fazendo-se necessário um incentivo ainda maior. Deste modo, o Meninas Digitais Regional Mato Grosso pretende continuar aplicando seu plano de ações, visando alcançar os 5 objetivos traçados e buscando ainda ampliar a sua atuação em números no estado.

\section{Referências}

INEP (2015) "Resumo Técnico da Educação Superior 2013”, Diertoria de Estatísticas Educacionais DEED, Instituto Nacional de Estudos e Pesquisas Educacionais Anísio Teixeira, Brasília-DF, 82 p.

Maciel, C., Bim, S. A. (2016) "Programa Meninas Digitais - ações para divulgar a Computação para meninas do ensino médio", In: Computer on the Beach 2016, Florianópolis, SC, p. 327-336.

Mendes, L. B., Figueiredo, K. S. (2016) "Analisando a Participação Feminina no Curso de Sistemas de Informação da Universidade Federal de Mato Grosso", In: Computer on the Beach 2016, Florianópolis, SC, p. 109-117.

SBC (2013) "Educação Superior em Computação, Estatísticas - 2013”, Relatório Técnico, Disponível em: <http://www.sbc.org.br/documentos $>$. 